\title{
Correction to: Personality trait and group emotion contagion based crowd simulation for emergency evacuation
}

\author{
Yan Mao ${ }^{1}$ - Shanwen Yang ${ }^{2,3} \cdot$ Zuning $\mathrm{Li}^{2,3}$. \\ Yongjian $\mathbf{L i}^{1}$
}

Published online: 26 July 2018

C) Springer Science+Business Media, LLC, part of Springer Nature 2018

\section{Correction to: Multimed Tools Appl (2018) \\ https://doi.org/10.1007/s11042-018-6069-3}

In the original publication, Figs. 1 and 4 contain an error. Figure 1 on page 7, in the lower right corner of the image below "Leader 2" should be corrected to "Group 2" instead of "Group 1". Figure 4 on page 12, on the left part of the image, "Group 3" should be corrected to "Group 1."

The correct figures are presented in this correction article.

Publisher's Note Springer Nature remains neutral with regard to jurisdictional claims in published maps and institutional affiliations.

The online version of the original article can be found at https://doi.org/10.1007/s11042-018-6069-3

Yongjian Li

yongjian_li@outlook.com

Yan Mao

maoyy85@163.com

1 School of Economics and Management, Southwest Jiaotong University, Chengdu, China

2 College of Movie and Media, Sichuan Normal University, Chengdu, China

3 Visual Computing and Virtual Reality Key Laboratory of Sichuan Province, Sichuan Normal University, Chengdu, China 

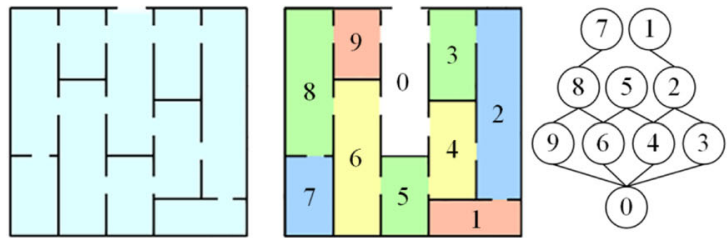

Environmental representation

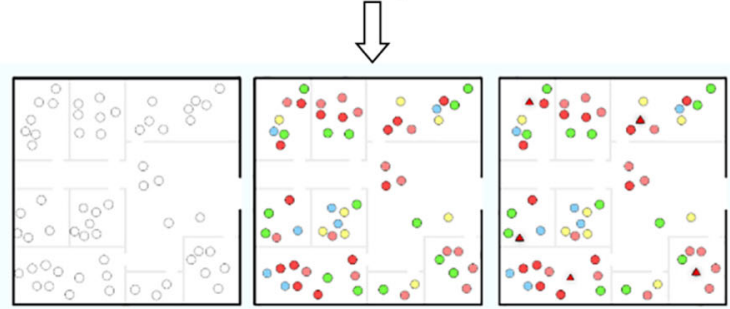

Crowd

Personality

Emotion

Initialization
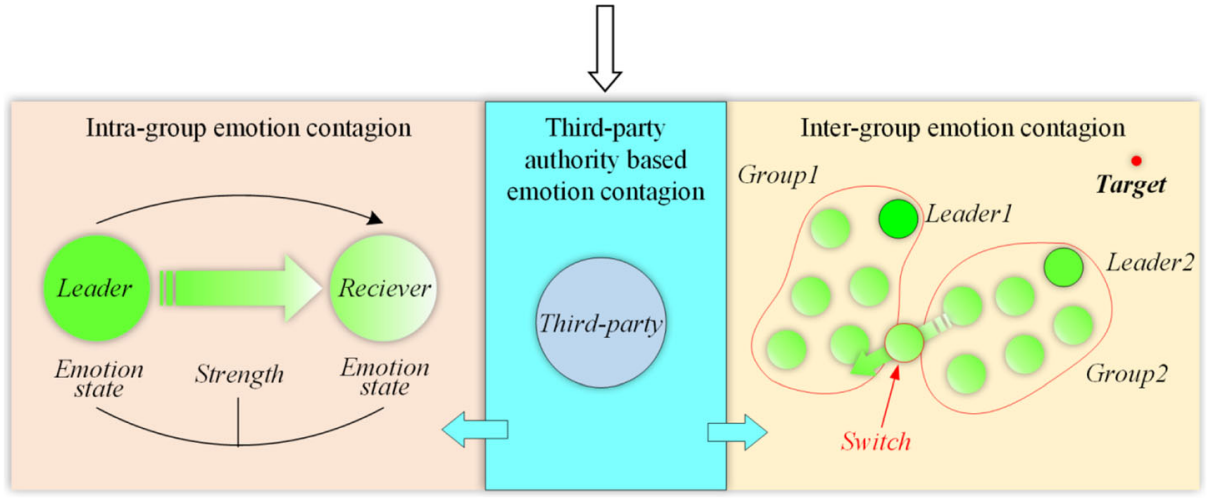

Fig. 1 The overview of our framework

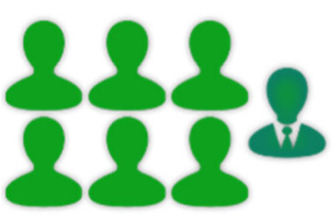

Group1

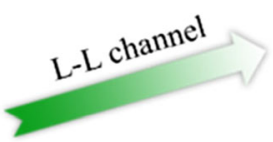

\section{$L-L c_{a n_{n} /}$}

Group2

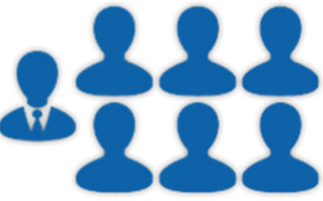

Group3

Fig. 4 Aspect of intra-group emotion contagion 